\title{
SYSTEMATIC ANALYSIS OF CHANGING VEHICLE EXTERIOR DIMENSIONS AND RELEVANT VEHICLE PROPORTIONS
}

\author{
Holder, Daniel \\ Institute for Engineering Design and Industrial Design, University of Stuttgart
}

\begin{abstract}
For the user perception of vehicles and consequently the success of automobile design, the body layout and especially the proportions of vehicles are pivotal. In the present study, the SAE main dimensions length (L108), wheelbase (L101), height (H100) and width (W103) of 697 vehicles from different OEMs were examined. The analysis reveals a tendency of increasing length, wheelbase and especially width of vehicles in recent years. Regarding the ratios of these dimensions there are clear correlations, as revealed by an analysis with linear regression. We find particular strong synchrony in the increases of the pairs W103 - L108 and L101 - L108 and lesser so between the ratio E = L108/L101 and the vehicle length. The latter can be explained by vehicles with a high L108 being less compact, i.e. the proportion E increases. Finally, it is discussed whether technological changes lead to revolutionary or evolutionary changes in dimensions. The historical development and the moderate proportional changes of BEVs indicate a measurable but evolutionary development. In contrast, disruptive technologies such as automated driving can significantly change the vehicle layout and thus encourage a more revolutionary change in proportions.
\end{abstract}

Keywords: Design cognition, User centred design, Industrial design, Vehicle Proportions, Design Technology Convergence

\section{Contact:}

Holder, Daniel

University of Stuttgart

Institute for Engineering Design and Industrial Design (IKTD)

Germany

daniel.holder@iktd.uni-stuttgart.de

Cite this article: Holder, D. (2021) 'Systematic Analysis of Changing Vehicle Exterior Dimensions and Relevant Vehicle Proportions', in Proceedings of the International Conference on Engineering Design (ICED21), Gothenburg, Sweden, 16-20 August 2021. DOI:10.1017/pds.2021.553 


\section{INTRODUCTION}

Product and automobile design have already been systematically analysed for many years. In his wellknown contribution "Seeking the Ideal Form", Bloch (1995) uses the subdivisions "shape, scale, tempo, proportion, materials, colour, reflectiveness, ornamentation and texture" which were first introduced by Davis (1987), and Kellaris and Kent (1993). According to Seeger (2014), the product design is divided into 4 different subgestalts, which build on one another. The subgestalts are layout, shape, colour and graphics of which the latter is extended by the surface (Holder, 2016). All subgestalts play a major role in product design and perception. The layout, however, fulfils an especially important function, given that the other subgestalts are not conceivable without it. Based on the layout of the vehicle design, the exterior dimensions and proportions are particularly striking as a characteristic feature.

Figure 1 shows an example of the impact of the layout and its proportions. On the left-hand side, the VW ID.4 shows a fully electric vehicle with battery packs in the underbody. The vehicle is higher than the ID.3 and its height is reminiscent of an SUV. Due to the large battery pack, the vehicle has a low ground clearance comparable to a sedan. The Mercedes-Benz F015 on the right is a study specifically designed for automated driving functions with seats facing each other. There is no steering wheel and the cabin is for relaxed sitting or working in. The design results in unusual proportions: The saloon has a very long wheelbase for the seating arrangement and hitherto untypical proportions.
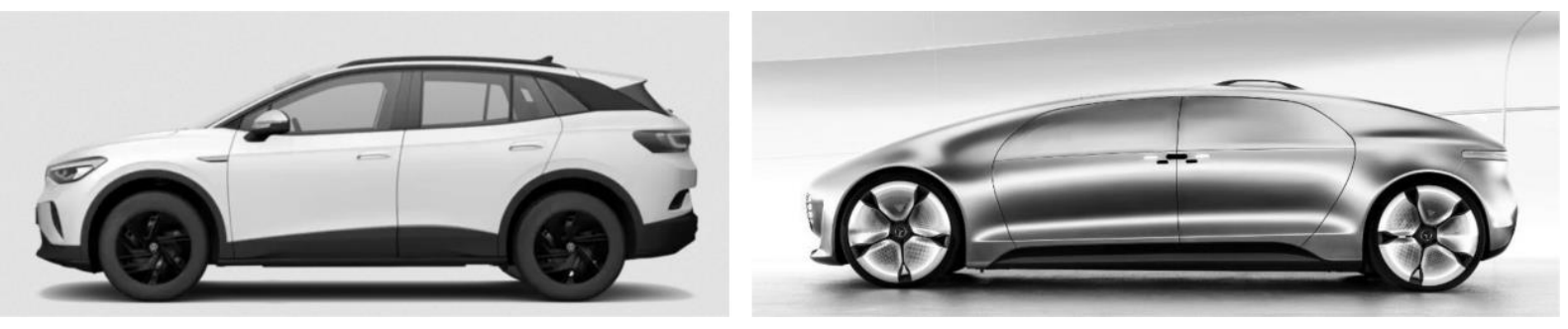

Figure 1. VW ID.4 and Mercedes-Benz F015 (Volkswagen, 2021; Mercedes-Benz, 2021)

As we have seen by way of example, vehicle proportions have a crucial influence on the perception and user impact of vehicles. This article examines the main dimensions of the vehicles and their proportions of the last approximately 45 years, how these dimensions have evolved and how they may evolve in the future. After a presentation of the state of the art, the methodical procedure of the systematic analysis is presented. Subsequently, the visualised results and statistical findings are presented and discussed.

\section{STATE OF THE ART}

The perception and emotional impact of a vehicle on the user depends largely on the vehicle proportions (Van Hooydonk, 2012). Unlike other design parameters, such as colour, the proportions are closely related to vehicle technology (Luccarelli et al., 2014a). The drive train, e.g., has strong influences on the layout, which can lead to different front and rear overhangs. For example, a combustion engine driven vehicle with front-wheel drive has a larger overhang at the front than a vehicle with rear-wheel drive (Kraus, 2007). In their comprehensive study, Luccarelli et al. (2014b) make it clear that alternative drive concepts such as the electric drive also have a significant influence on vehicle proportions.

Already during the technological development of electrification, the question arose to what extent the design and layout of the vehicles would change evolutionary or revolutionary. This and other technological impulses for change are often divided into approaches based on conversion and purpose design (Wallentowitz et al., 2010). Conversion design maintains the existing vehicle architecture and tries to integrate the new technologies into this existing architecture. In most cases the proportions remain the same. In contrast to this, purpose design rethinks the vehicle architecture fundamentally. In the example of the battery electric vehicle (BEV) described above, this means that the integration of battery technology may influence the vehicle architecture (Holder and Maier, 2012). Thus, batteries in sandwich construction affect the vehicle design in such a way that the vehicle height increases and thus also the proportions change (Morche et al., 2013). The purpose design approach usually creates vehicle proportions that differ significantly from vehicles with conventional technology. It is undisputed that future, fully automated vehicles (SAE levels 4 and 5) will have different proportions, such as an extended wheelbase (Tzivanopoulos et al., 2015). Macey and Wardle (2014) emphasize that for new design projects, the architecture should be rethought every time "to make an exciting 
statement about its intended function." In a study by Jung (2018), the vehicle dimensions and proportions of Japanese and German automobiles are compared by means of length and height. For the analysis, the vehicle proportions are shown as ellipses over the silhouette, as suggested by Elam (2001). Jung (2018) showed that the harmonic metric "golden ratio" is not a frequently encountered proportion. Furthermore, it became apparent that Japanese vehicles have a shorter length to height ratio than German vehicles. Krasteva et al. (2017) focus in their work on the proportions of automobiles on defining the main proportions as enveloping cuboids around the vehicle and extend this definition by secondary proportions within this body. The attention to the main proportions of the enveloping cuboid is a practicable approach, which will also be used in the subsequent analysis.

Barnum and Mattson (2010) present a computer-aided methodology for capturing and integrating designer preferences in a numerical search for design concepts. For this purpose they parametrized modular vehicles. The main focus of the study is form optimisation as an interplay of an evaluation by designers with an adaptive algorithm. Although the proportional consideration has not been evaluated nor does it play a role in the paper, the results are interesting, because the study shows that unusual designs are disliked. Many studies have shown that unusual designs are generally rated as unattractive by non-designers (Oehme, 2011; Diels et al., 2013; Holder, 2016). The observation that unusual designs are initially displeasing to the user is indeed in line with expectations. Therefore, after looking back on the historical development, this paper will also address the importance of proportional changes.

Even if the proportions are undisputedly essential for the vehicle shape, it has become clear that there are only a few studies systematically taking care of the analysis of the vehicle proportions or harmonic metrics. Especially the view on the development of the main dimensions and their relations to each other has not been investigated in this way so far. The present paper aims to provide an answer to this issue.

\section{METHODICAL ANALYSIS}

As explained at the beginning and substantiated by the state of the art, the proportions of a vehicle are very important for the impact of the exterior design and have therefore been analysed in detail. It is crucial for a meaningful analysis of vehicle proportions to examine numerous vehicles from different manufacturers. Primarily vehicles from European and Asian brands were considered. In total, 697 vehicles between 1972 and 2020 by 21 OEMs were examined (cf. Table 1). The dimensions were acquired from publicly accessible online databases and cross-checked for reliability. The data comprises representatives of all consumer vehicle classes typically found on public roads.

Table 1. Vehicle database for the dimension and proportion analysis

\begin{tabular}{|c|c|}
\hline OEM & Models \\
\hline Audi & $\begin{array}{l}\text { A1, A3, A4, A5, A6, A7, A8, E-Tron GE, E-Tron sportsback, } \\
\text { Q2, Q3, Q5, Q7, Q8, R8, TT }\end{array}$ \\
\hline BMW & $\begin{array}{l}\text { 1, 2, 3, 4, 5, 6, 7, } 8 \text { Series, i3, i8, M2, M3, M4, M5, X1, X2, } \\
\text { X3, X4, X5, X6, X7, Z4 }\end{array}$ \\
\hline Citroen & $\begin{array}{l}\text { Berlingo, C1, C2, C3, C3 Aircross, C4, C4 Cactus, C5, C5 } \\
\text { Aircross, C6, C8, C-Crosser, C-Elysee, C-Zero, DS3, DS4, } \\
\text { DS5, DS7, Evasion, Jumpy, Saxo, Spacetourer, Sxara }\end{array}$ \\
\hline Fiat & $\begin{array}{l}124 \text { Spider, 500, 500E, 500X, Bravo, Cinquecento, Doblo, } \\
\text { Freemont, Fullback, Multipla, Panda, Punto, Qubo, Scudo, } \\
\text { Sedici, Talento, Tipo }\end{array}$ \\
\hline Ford & $\begin{array}{l}\text { B-MAX, C-MAX, Cougar, EcoSport, Edge, Explorer, Fiesta, } \\
\text { Focus, Fusion, Galaxy, Ka+, Kuga, Maverick, Mondeo, } \\
\text { Mustang Mach-E, Probe, Puma, Ranger, Scorpio, S-MAX, } \\
\text { Streetka, Transit Courier, Windstar }\end{array}$ \\
\hline Hyundai & $\begin{array}{l}\text { Accent, Atos, Atos Prime, Dynasty, Genesis, Getz, i10, i20, } \\
\text { i30, i40, ix20, ix35, ix55, Ioniq, Kona, Nexo, Santa Fe, Sonata, } \\
\text { Tucson, Veloster }\end{array}$ \\
\hline Jaguar & E-, F-, I-Pace, F-, S-, X-Type, XE, XF, XJ, XK \\
\hline Mazda & $\begin{array}{l}\text { 2, 3, 5, 6, BT-50, CX-3, CX-5, CX-7, CX-30, MX-5, MX-30, } \\
\text { Premacy }\end{array}$ \\
\hline $\begin{array}{l}\text { Mercedes- } \\
\text { Benz }\end{array}$ & $\begin{array}{l}\text { A-, B-, C-, E-, G-, M-, R-, S-, V-, X-Class, CLA, CLC, CLK, } \\
\text { CLS, EQC, GLA, GLB, GLC, GLE, GLK, GLS, SL, SLC, } \\
\text { SLK }\end{array}$ \\
\hline Mini & $\begin{array}{l}\text { Clubman, Cooper, Countryman, Coupe, Mini Electric, } \\
\text { Paceman }\end{array}$ \\
\hline Nissan & $\begin{array}{l}\text { 350Z, 370Z, Almera, Ariya, Evalia, GT-R, Juke, Leaf, Micra, } \\
\text { Murano, Navara, Note, Pathfinder, Pixo, Primera, Pulsar, } \\
\text { Qashqai, Tiida, X-Trail }\end{array}$ \\
\hline
\end{tabular}

\begin{tabular}{|c|c|}
\hline OEM & Models \\
\hline Opel & $\begin{array}{l}\text { Adam, Agila, Ampera, Antara, Astra, Calibra, Campo, } \\
\text { Cascada, Combo, Corsa, Corsa-e, Crossland X, Frontera, } \\
\text { Grandland X, GT, Insignia, Karl, Meriva, Mokka, Mokka-e, } \\
\text { Omega, Signum, Sintra, Speedster, Tigra, Vectra, Vivaro, } \\
\text { Zafira, Zafira Life }\end{array}$ \\
\hline Polestar & Polestar 1, Polestar 2 \\
\hline Renault & $\begin{array}{l}\text { Alaskan, Capture, Clio, Espace, Fluence, Kadjar, Kangoo, } \\
\text { Kangoo Z. E., Koleos, Laguna, Latitude, Megane, Modus, } \\
\text { Scenic, Talisman, Trafic, Twingo, Twingo electric, Twizy, Vel } \\
\text { Satis, Wind, Zoe }\end{array}$ \\
\hline Seat & $\begin{array}{l}\text { Alhambra, Altea, Arona, Arosa, Ateca, Cordoba, Exeo, Ibiza, } \\
\text { Inca, Leon, Mii, Mii Electric, Tarraco, Toledo, }\end{array}$ \\
\hline Skoda & $\begin{array}{l}\text { Citigo, Enyag iV, Fabia, Felicia, Kamiq, Karoq, Kodiaq, } \\
\text { Octavia, Rapid, Roomster, Scala, Superb, Yetia }\end{array}$ \\
\hline smart & EQ Forfour, EQ Fortwo, Forfour, Fortwo, Roadster \\
\hline Tesla & Model 3, Model S, Model X, Model Y, Roadster \\
\hline Toyota & $\begin{array}{l}\text { Auris, Avensis, Aygo, Camry, Carina, Celica, C-HR, Corolla, } \\
\text { Corolla Sedan, GT86, Hilux, iQ, Land Cruiser, Mark II, Mirai, } \\
\text { MR2, Prius, Proace, RAV4, Supra, Urban Cruiser, Verso, } \\
\text { Yaris }\end{array}$ \\
\hline Volvo & $\begin{array}{l}\mathrm{C} 30, \mathrm{C} 70, \mathrm{~S} 40, \mathrm{~S} 60, \mathrm{~S} 80, \mathrm{~S} 90, \mathrm{~V} 40, \mathrm{~V} 60, \mathrm{~V} 70, \mathrm{~V} 90, \mathrm{XC} 40, \\
\text { XC40 Recharge, XC60, XC70, XC90 }\end{array}$ \\
\hline VW & $\begin{array}{l}\text { Amarok, Arteon, Beetle, Bus, Caddy, Golf, ID.3, ID.4, Jetta, } \\
\text { Passat, Phaeton, Phideon, Polo, Scirocco, Sharan, T-Cross, } \\
\text { Tiguan, Touareg, Touran, } \\
\text { T-Roc, up! }\end{array}$ \\
\hline
\end{tabular}


In the case of size ranges based, for example, on different derivatives such as hatchbacks or station wagons, the larger dimension was selected in each case. Some models have been on the market for many years and therefore appear in the analysis with different proportions. The Mercedes-Benz EClass, for example, takes into account the main dimensions of seven generations of vehicles: W124, W210, W211, W212, W212, W463, W460. For the analysis, the main dimensions length L108, width W103, height H100 and the wheelbase L101 were considered according to SAE International (2009) (cf. Figure 2). These dimensions are stylistically indicative of the shape of the vehicle and vehicle classifications are by and large based on them (Achleitner et al., 2013). They are available for all vehicles and thus a representative analysis is possible. In view of the technological changes mentioned above, the dimensions of BEVs and fuel cell vehicles were also considered (cf. Table 1). However, this group is so small $(4.9 \%)$ that a specific statistical evaluation in Section 4 was not appropriate.

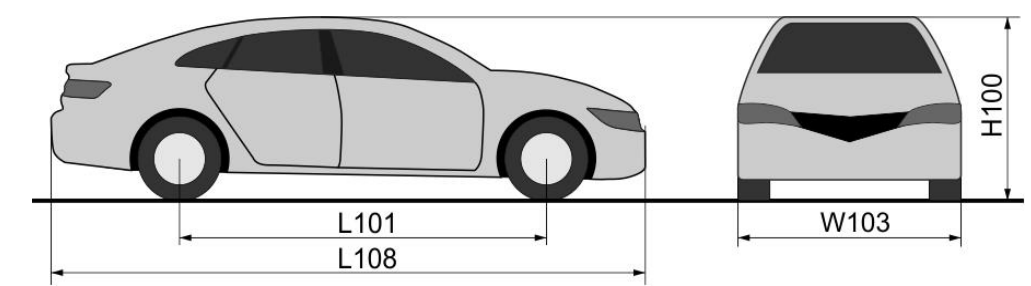

Figure 2. L101, L108, H100, W103 (own visualisation according to SAE International, 2009)

Of additional interest is the ratio of the elongation $\mathrm{E}$, which is defined as follows:

$$
E=\frac{L 108}{L 101}
$$

This ratio between wheelbase and vehicle length is a measure of the compactness of the vehicle in terms of vehicle overhang. A large ratio increases the perceived overhang of the vehicle and vice versa.

In summary, the methodical analysis examines the vehicles with regard to their date of publication SOP and the described SAE main dimensions. For the inferential analysis, linear regression is used and the corresponding requirements (Kronthaler, 2015) are checked. The correlations were calculated according to Bravais-Pearson (Fahrmeir et al., 2016).

\section{RESULTS OF THE SYSTEMATIC DIMENSIONAL ANALYSIS}

The results of the analysis are presented below. First the historical development of the vehicle dimensions was examined and the observable correlations calculated. Afterwards, the proportional relationships of the investigated vehicles were considered and harmonic relationships of the vehicle dimensions were identified.

\subsection{Historical development of the exterior dimensions}

The historical review examined how the main SAE measures presented in Section 3 have developed over the years. All three main dimensions L108, W103 and H100 and also the wheelbase L101 exhibit an increase over the years. Figure 3 shows the distribution of the length measurements of all 697 vehicles over the SOP and the trend line. In the same way, Figure 3 shows the development of the wheelbase over the SOP. The distribution also shows a wide spread of measurements, which can be explained by the different consumer vehicle classes from small cars to vans and was deliberately not sorted out in the evaluation in order to represent a typical selection of vehicles in the street scene.

In a first step, the increase in dimensions was investigated using linear regression between the dependent variable SOP and the independent variables L108, W103, H100 and L101 (cf. Table 2). Firstly, the requirements for a regression analysis have been examined: The regressions are linear, the sample is random (cf. vehicle selection) and there is no systematic shift, the standardised residuals scatter unsystematically. The test for homoscedasticity shows that all dimensions do not meet this criterion and instead show heteroscedasticity. Additionally, the independent variables correlate with each other. This aspect is examined in detail in the regression analysis in Section 4.2. Finally, when checking the standardised residuals, largely homogeneous distributions are available for all dimensions. On the basis of these results, trends can be identified with regard to the correlations, but no resilient predictions for the connections between the dimensions and SOP can be made. Table 2 shows the results of the correlation and significance test. The increase in measures over the SOP is significant in all cases. If we look at the 
coefficient of determination $\mathrm{R}^{2}$ of the individual regression analyses, we find that a statement can be made about the width W103 with highest confidence. The result is discussed in Section 5.1.
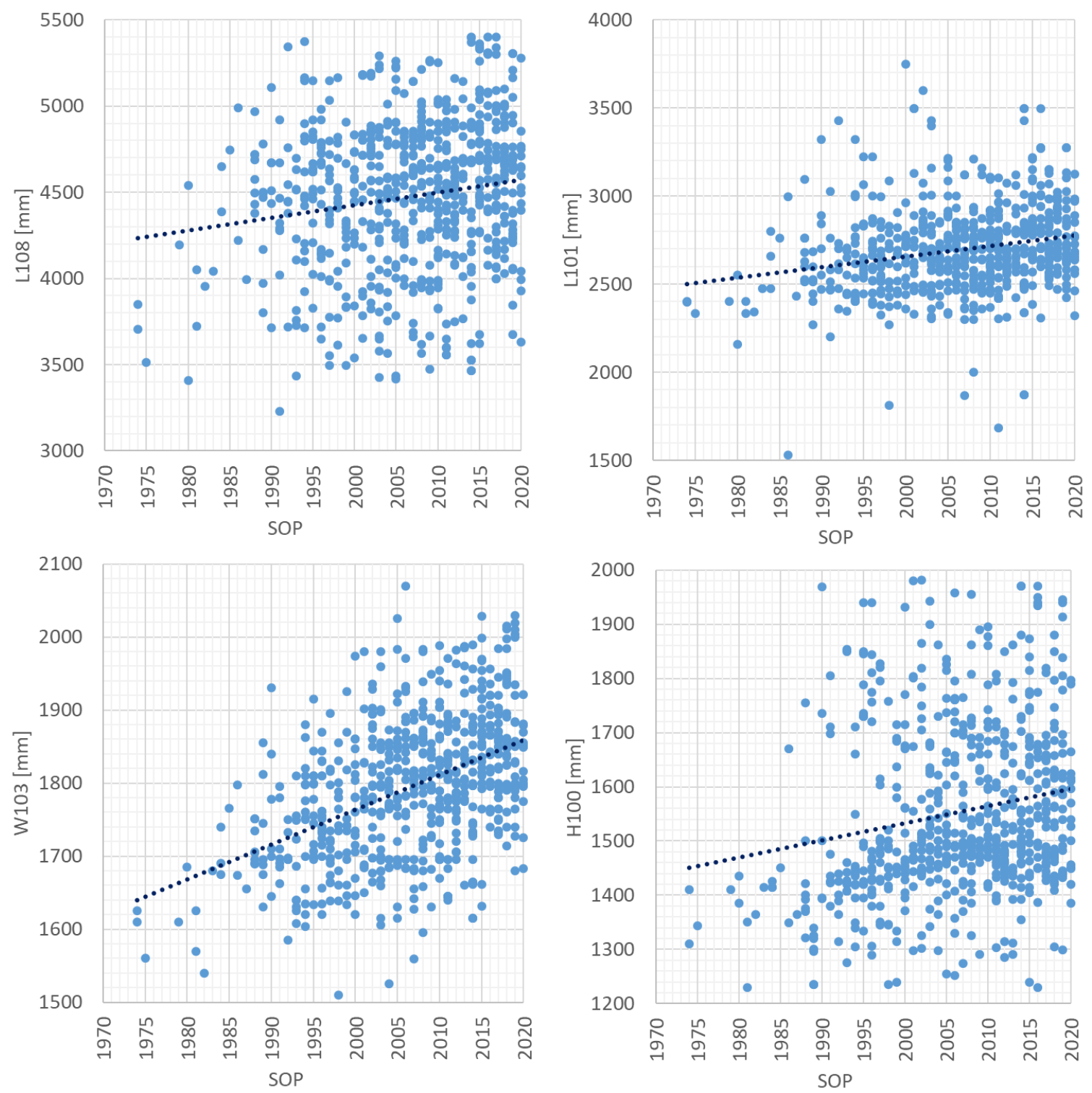

Figure 3. Development of L108, L101, W103 and H100 over SOP

Table 2. Regression analysis for the exterior dimensions and SOPS

\begin{tabular}{|l|r|r|r|r|}
\hline & L108 - SOP & W103 - SOP & H100 - SOP & L101 - SOP \\
\hline correlation & 0.148 & 0,416 & 0.162 & 0.221 \\
\hline $\mathrm{t}$-value & 3.939 & 12,049 & 4.320 & 5.977 \\
\hline $\mathrm{p}$-value & 0.000 & 0.000 & 0.000 & 0.000 \\
\hline $\mathrm{R}^{2}$ & 0.022 & 0.173 & 0.026 & 0.049 \\
\hline
\end{tabular}

\subsection{Proportional relationship of the exterior dimensions}

In the following analysis, the dimensions were considered in relation to each other and the correlations were checked. The proportions of all 697 vehicles are displayed in Figure 4. The visual analysis shows that the width W103, the height H100 and the wheelbase L101 correlate with the length L108. There also seems to be a strong correlation between wheelbase L101 and width W103. The relationship of width W103 and wheelbase L101 to height H100 does not seem to be as strong.

The diagram in Figure 5 also shows the interaction of E to L108 and W103. The ratio E to H100 does not give a meaningful picture and is not considered further. It can be seen that long and wide vehicles also have longer overhangs on average, which is why the quotient $\mathrm{E}$ is higher in those cases. 

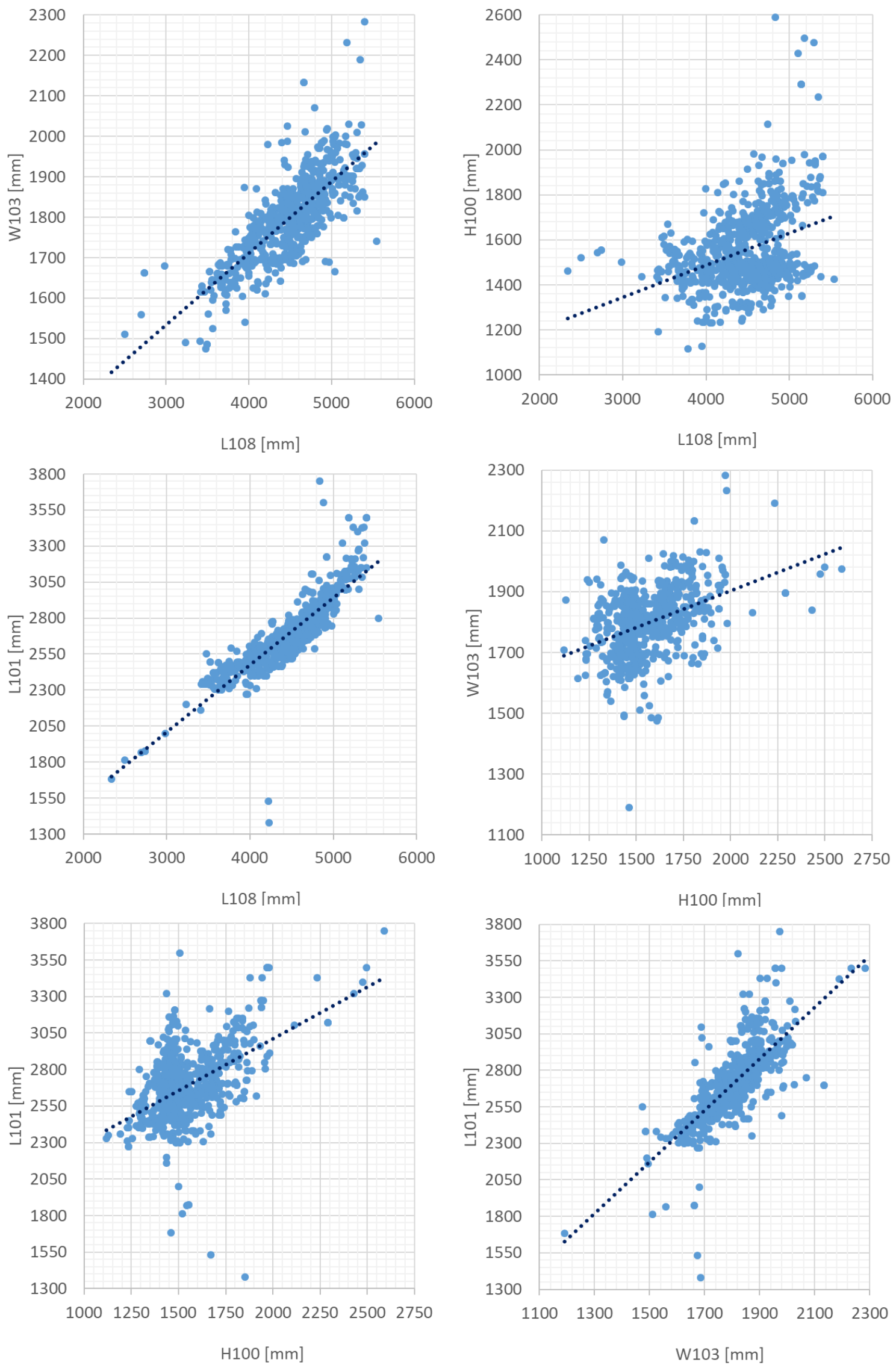

Figure 4. Proportions: W103 versus L108, H100 versus L108, L101 versus L108, W103 versus H100, L101 versus H100, L101 versus W103 

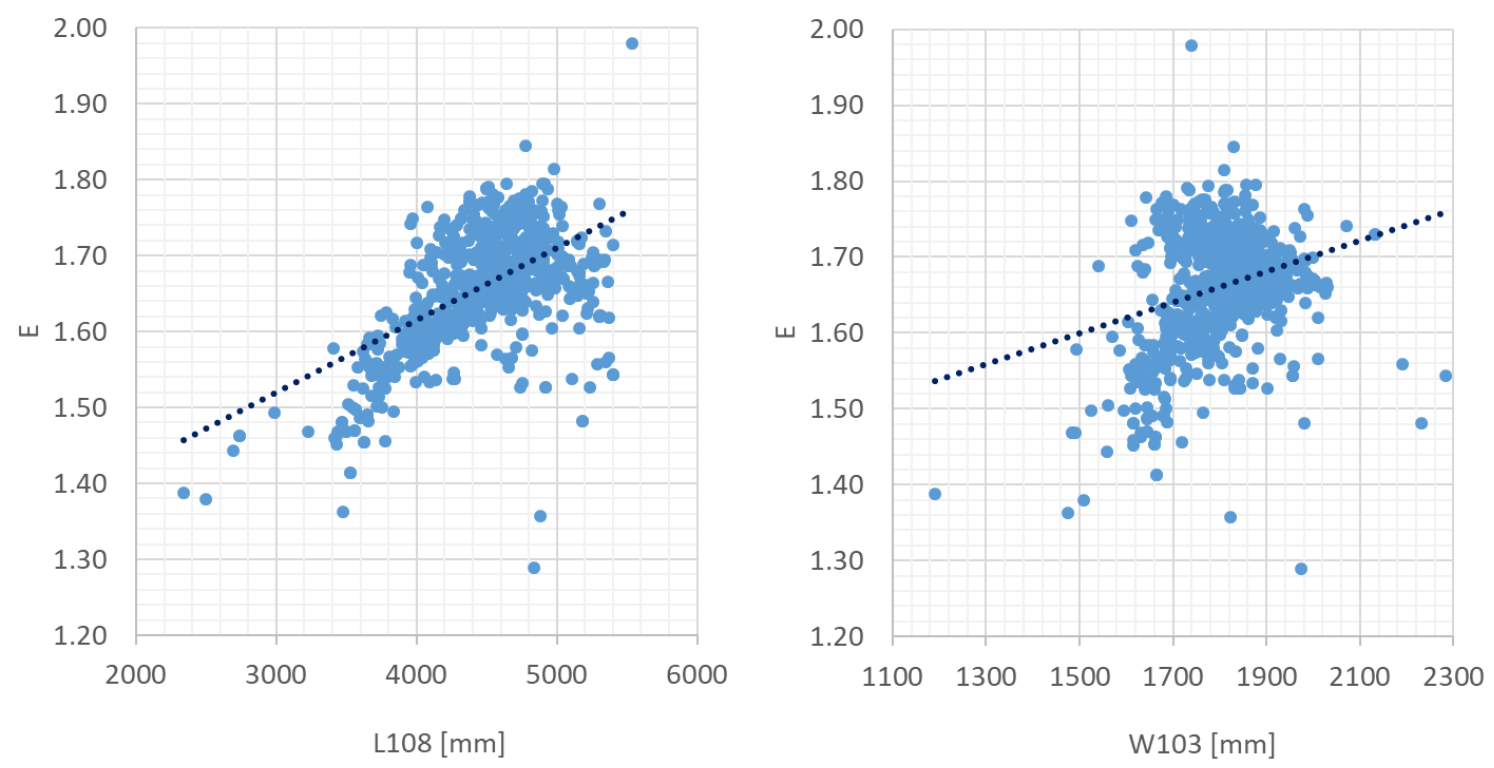

Figure 5. Display of the proportions: E versus $L 108$ and $E$ versus $W 103$

These relationships were also statistically evaluated in the same way as in Section 4.1. Table 3 shows the results of regression analysis. In contrast to the regression analysis in Section 4.1, in this case the conditions for a statistical relationship in the sense of a linear regression are fulfilled for almost all dimensions. Only the ratio of E to L108 results in heteroscedasticity when testing for homoscedasticity. Due to the fulfilled regression criteria, it is also useful at this point to take a closer look at the coefficient of determination $\mathrm{R}^{2}$. The proportions W103 to L108, L101 to L108 and L101 to W103 can each be described by the regression line with a probability of $55.9 \%$ to $74.8 \%$.

Table 3. Regression analysis for the particular exterior dimensions and proportions

\begin{tabular}{|l|r|r|r|r|r|r|r|r|}
\hline & $\begin{array}{c}\text { W103 - } \\
\text { L108 }\end{array}$ & $\begin{array}{c}\text { H100 - } \\
\text { L108 }\end{array}$ & \multicolumn{1}{c|}{$\begin{array}{c}\text { L101- } \\
\text { L108 }\end{array}$} & $\begin{array}{c}\text { W103 - } \\
\text { H100 }\end{array}$ & $\begin{array}{c}\text { L101- } \\
\text { H100 }\end{array}$ & $\begin{array}{c}\text { L101- } \\
\text { W103 }\end{array}$ & $\begin{array}{c}\text { E - } \\
\text { L108 }\end{array}$ & $\begin{array}{c}\text { E - } \\
\text { W103 }\end{array}$ \\
\hline correlation & 0.775 & 0.365 & 0.865 & 0.414 & 0.512 & 0.748 & 0.421 & 0.206 \\
\hline t-value & 32.372 & 10.343 & 45.398 & 11.977 & 15.707 & 29.704 & 12.247 & 5.561 \\
\hline p-value & 0.000 & 0.000 & 0.000 & 0.000 & 0.000 & 0.000 & 0.000 & 0.000 \\
\hline $\mathrm{R}^{2}$ & 0.601 & 0.133 & 0.748 & 0.171 & 0.262 & 0,559 & 0.178 & 0.043 \\
\hline
\end{tabular}

\subsection{Proportional relationship of the exterior dimensions of current vehicles}

The vehicle data were filtered to check whether the correlations examined are also a currently valid correlation. The filter criterion was the SOP. The median of the model lifetimes is 6 years (the mean is 4.6 years). For the current vehicles, only models with an SOP from 2014 onwards were taken into account. But also the analysis of the resulting 202 vehicles shows a very similar picture (cf. Table 4). In examining the conditions, the criteria are also broadly met. However, there are first indications that the criteria are at least not fully met. For example, the pairs H100-L108, L101-W103, E-L108 and EW103 show slight autocorrelations and H100-L108, W103-H100 and E-L108 may show a very weak heteroscedasticity. Focussing on $\mathrm{R}^{2}$, the proportions W103 to L108, L101 to L108 and L101 to W103 result in high coefficients of determination: $64.6 \%, 86.7 \%$ and $62.7 \%$.

Table 4. Regression analysis for the particular exterior dimensions and proportions of current vehicles

\begin{tabular}{|l|r|r|r|r|r|r|r|r|}
\hline & $\begin{array}{c}\text { W103 - } \\
\text { L108 }\end{array}$ & $\begin{array}{c}\text { H100 - } \\
\text { L108 }\end{array}$ & $\begin{array}{c}\text { L101- } \\
\text { L108 }\end{array}$ & $\begin{array}{c}\text { W103 - } \\
\text { H100 }\end{array}$ & $\begin{array}{c}\text { L101- } \\
\text { H100 }\end{array}$ & $\begin{array}{c}\text { L101- } \\
\text { W103 }\end{array}$ & $\begin{array}{c}\text { E - } \\
\text { L108 }\end{array}$ & $\begin{array}{c}\text { E - } \\
\text { W103 }\end{array}$ \\
\hline correlation & 0.804 & 0.450 & 0.804 & 0.445 & 0.571 & 0.792 & 0.594 & 0.385 \\
\hline t-value & 19.098 & 7.121 & 19.098 & 7.024 & 9.846 & 18.355 & 10.432 & 5.900 \\
\hline $\mathrm{p}$-value & 0.000 & 0.000 & 0.000 & 0.000 & 0.000 & 0.000 & 0.000 & 0.000 \\
\hline $\mathrm{R}^{2}$ & 0.646 & 0.202 & 0.867 & 0.198 & 0.326 & 0.627 & 0.352 & 0.148 \\
\hline
\end{tabular}




\subsection{Evaluation of the averaged proportions regarding harmonic metrics}

Finally, the mean values and medians of all investigated proportions of exterior dimensions were examined and the result of this investigation is shown in Table 5. Taking into account known proportions, it was found that in two cases the ratio was close to the golden ratio. Studies on individual products repeatedly show the use of the golden ratio 1.618 (Ali and Liem 2014). The fact that the averaged proportion $\mathrm{E}$ is based on a very broad database makes this statement all the more remarkable. For this part of the investigation, all vehicles were considered. A limitation to current vehicles gives an almost identical picture and was therefore not further pursued.

Table 5. Mean value and median for the analysed proportions of the vehicles

\begin{tabular}{|l|r|r|r|r|r|r|}
\hline & E $=$ L108/L101 & L108/W103 & L108/H100 & W103/H100 & L101/H100 & L101/W103 \\
\hline mean value & 1.660 & 2.476 & 2.856 & 1.154 & 1.728 & 1.495 \\
\hline median & 1.667 & 2.507 & 2.869 & 1.163 & 1.733 & 1.492 \\
\hline
\end{tabular}

\section{DISCUSSION OF THE RESULTS AND OF FUTURE PROPORTIONS}

After presenting the outcomes of the analysis of vehicle dimensions and proportions, the results will be discussed and in a further step, utilized together with the state of the art and a technological forecast as means to review the potential development of the main dimensions and proportions.

\subsection{Discussion of the results}

As can be seen from the visual analysis, all the main exterior dimensions have increased over time and although this development is obvious, a strict linear regression cannot be deduced. The increase is most obvious in the measure W103, where the linear regression has a coefficient of determination of $17.3 \%$. This is in line with the perception in everyday traffic, where this trends creates problem situations time and again. Vehicles with correspondingly large dimensions have to navigate, for example, too narrow driveways in car parks. The wheelbase L101 has also increased continuously, which benefited interior comfort. As of today, major changes in proportions have not yet occurred. However, it must be taken into account that purely electric vehicles are still rare and that vehicles from SAE Level 4 upwards are almost non-existent. As can be seen in Section 4.2, longer vehicles also have a greater width, height and wheelbase. There is a particularly strong correlation between width and length as well as between wheelbase and length. It was foreseeable that an increase in size of a vehicle would not occur in one dimension alone. The general correlations are therefore trivial, but what is striking are the characteristics of the correlations. The strong correlation between W103 and L108 indicates that the vehicle length is accompanied by growth in width, which can be attributed to the increased interior space and comfort requirements. The fact that longer vehicles also have a longer wheelbase is a plausible relationship, as the longer wheelbase is often necessary for the use of the interior space as well. There is a strong correlation between the wheelbase and the width. This correlation could also be an indirect correlation, because the width and length of the vehicle are also strongly correlated, which in turn influences the correlation of W103 to L101. Finally, the relationship of the ratio E to vehicle length also shows a clear correlation. This can be explained by the fact that longer vehicles often have a larger boot volume and therefore a comparatively large rear overhang. This has an increasing effect on the ratio $\mathrm{E}$. The results on current vehicles confirm the trends described above and show that the proportional relationships have changed little over time, even if the main measurements by themselves have increased.

It now remains to be seen whether in the future the vehicle proportions could be subject to change, stemming from technological advancements and their consequent demands on the dimensions. The calculation of the mean value of $\mathrm{E}$ resulted in a ratio close to the golden ratio. Even if the result is interesting on its own and could possibly lead to a harmonious perception, it must also be mentioned that the ratio $\mathrm{E}$ is not the only proportion that is perceived. Besides L101 and L108, the overhangs in front and behind are also of central importance concerning the vehicle side view.

\subsection{Functional effects of a change in the main proportions}

Looking at dimensions and proportions from around 45 years ago, it becomes clear that dimensions have changed more in an evolutionary than a revolutionary way. During this time, vehicles have been improved, they have become more comfortable and have been given more functions, but a drastic proportional change has not occurred. The percentage rate of BEVs is still too low for a statistical 
statement. However, the fact that many BEVs come onto the market as SUVs supports the statement in Section 2 that a slight proportional change can also occur here. Due to the fact that SUVs are already very popular, a revolution does not seem to be foreseeable at this point. Still, the exciting question remains: Will vehicle design continue in these footsteps? In support of the affirmative is the fact that technical innovations are only gradually finding their way into the broad mass of vehicles and that the customer will not necessarily support even drastic changes.

On the other hand, however, there are indications that the proportions of a vehicle will change due to one or the other technical innovation. The technology of automated driving probably has the greatest potential for introducing change. The reason being, that the use case setting is systematically different from all previous forms of vehicle usage, which is visualised in Figure 6. At the beginning of automobile development the customer was the passenger and the vehicle was driven by a chauffeur. Characteristic for this early period is the famous sentence by Gottlieb Daimler: "The global demand for cars will not exceed one million worldwide - if for nothing else due to a lack of chauffeurs" (Löhr, 2016). Over time this has morphed into the situation, where the customer drives the vehicle themselves. However, rising levels of automation are associated with high levels of change and the vehicle of the distant future may then only contain passengers. As can be seen in Figure 6, there is a distinct possibility that the defined elongation $\mathrm{E}$, in this case for long vehicles, might decrease significantly, i.e. the above untried relationship would be reversed and the proportion and effect of the vehicle exterior could change drastically. This would also resolve the observed resemblance of the proportion $\mathrm{E}$ to the golden ratio.

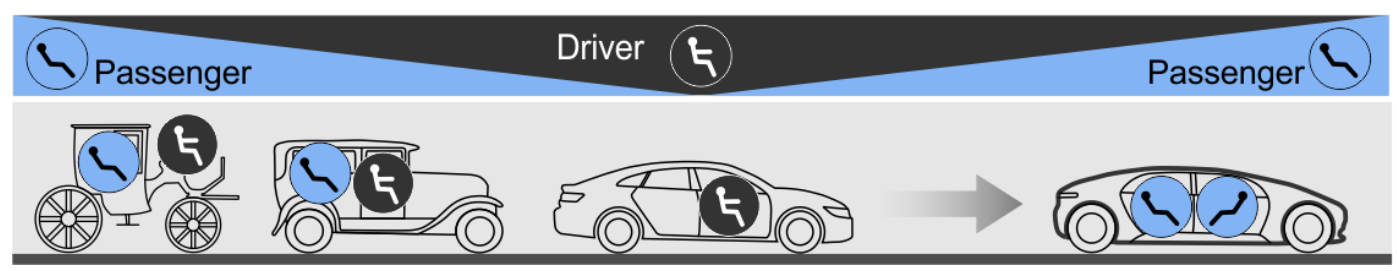

Figure 6. Historical development: from passenger to driver and back again

\section{CONCLUSSION AND OUTLOOK}

This study presented a comprehensive investigation of the exterior dimensions of vehicles. It has become clear that the vehicle dimensions have not changed completely over the past years, but increased significantly, especially in terms of vehicle width. Furthermore, the analysis yielded proportional relationships between the main dimensions of the vehicles, among which the ratios of W103 to L108, L101 to L108 and L101 to W103 were particularly striking. It is noteworthy that the ratio E = L108/L101 on average is very close to the golden ratio not only for the collective of vehicles studied here but also for the current model generation. The golden ratio appears in many otherwise unrelated situations in nature, architecture and design. Although no revolutionary changes in proportions have been observed here, future technological developments, such as automated driving, may well lead to changes in proportions. For this reason and building on this and an already existing study (Holder, 2016), it seems obvious and purposeful to investigate, which additional parameters will lead to proportional changes. Beyond that, the question arises which new, possible harmonies might be associated with these changes. With the help of the study results, new vehicle concepts can be classified very well at the beginning of the development process with regard to the usual proportions. In case of deviations, further proportion investigations or acceptance studies are conceivable. We are also planning to investigate other dimensions and proportions in connection with vehicle overhangs and the green house.

\section{REFERENCES}

Achleitner, A.; Antony, P.; Ascher, F.; Berger, E.; Burgers, C.; Döllner, G.; Friedrich, J. K. H.; Futschik, H. D.; Gruber, M.; Kiesgen, G.; Mohrdieck C. H.; Noreikat, K. E.; Schulze, H.; Wagner, M.; Wöhr, M.: Formen und neue Konzepte, In: Braess, H.-H.; Seiffert, U. (Eds.) (2013), Vieweg-Handbuch Kraftfahrzeugtechnik, Springer Vieweg, Wiesbaden., pp.119-219. http://doi.org/10.1007/978-3-658-01691-3

Ali, A. and Liem, A. (2014), "The use of formal aesthetic principles as a tool for design conceptualisation and detailing", Espoo, Finland.

Barnum, G.J. and Mattson, C.A. (2010), “A Computationally Assisted Methodology for Preference-Guided Conceptual Design”, Journal of Mechanical Design, Vol. 132 No. 12, p. 12003-1-9. https://doi.org/10.1115/1.4002838 
Bloch, P.H. (1995), "Seeking the ideal form: Product design and consumer response”, Journal of Marketing, Jul No. 59, pp. 16-29. http://doi.org/10.2307/1252116

Davis, M.L. (1996), Visual design in dress, Prentice Hall, Upper Saddle River, N.J.

Diels, C., Siamatas, A. and Johnson, C. (2013), Designing for the new vehicle DNA: Evaluation of the MAYA principle for the rapid adoption of sustainable vehicles, 5th IASDR World Conference on Design Research, Tokyo, Japan. http://doi.org/10.13140/RG.2.1.2882.2889

Elam, K. (2001), Geometry of design: Studies in proportion and composition, Design briefs Essential texts on design, Princeton Architectural Press, New York, NY.

Fahrmeir, L., Heumann, C., Künstler, R., Pigeot, I. and Tutz, G. (2016), Statistik: Der Weg zur Datenanalyse, Springer-Lehrbuch, 8., überarbeitete und ergänzte Auflage, Springer Spektrum, Berlin, Heidelberg. http://doi.org/10.1007/978-3-662-50372-0

Holder, D. (2016), Gefallensurteil und Blickanalyse zum Fahrzeugdesign zukünftiger Aufbaugestalten anhand einer technischen Prognose, Stuttgart, Universität Stuttgart.

Holder, D. and Maier, T. (2012), "Neue Batteriekonzepte ein nutzerzentrierter Ansatz”, MTZ - Motortechnische Zeitschrift, Vol. 73 No. 10, pp. 762-766. http://doi.org/10.1007/s35146-012-0478-z

Jung, J.Y. (2018), “The Influence of Proportion Preference in Automotive Design: Comparison Between Japanese and German Automobiles”, Science of Emotion and Sensibility, Vol. 21 No. 1, pp. 89-96. http://doi.org/10.14695/KJSOS.2018.21.1.89

Kellaris, James J. and Robert J. Kent (1993), "Exploring Responses Elicited by Music Varying in Tempo, Tonality, and Texture," Journal of Consumer Psychology, 2 (4), 381-401. https://doi.org/10.1016/S10577408(08)80068-X

Krasteva, P., Inkermann, D., Vietor, T. and Tzivanopoulos, T. (2017), "Zielkonfliktidentifikation zwischen Design, Technik und Ergonomie - Ein Lösungsansatz am Beispiel der Fahrzeugkonzeption”, in Stuttgarter Symposium für Produktentwicklung 2017, pp. 1-10.

Kraus, W. (2007), “Grundsätzliche Aspekte des Automobildesigns”, In: Braess, H.-H. (Ed.), Automobildesign und Technik: Formgebung, Funktionalität, Technik, Vieweg, Wiesbaden. pp. 30-65. http://doi.org/10.1007/978-3-8348-9411-3

Kronthaler, F. (2015), Statistik angewandt: Datenanalyse ist (k)eine Kunst Excel Edition, Springer-Lehrbuch, Aufl. 2016, Springer, Berlin.

Löhr, K. (2016), "The Science of Innovation. A Comprehensive Approach for Innovation Management", De Gruyter Oldenbourg, Berlin, Boston.

Luccarelli, M., Lienkamp, M., Matt, D. and Russo Spena, P. (2014a), “Automotive Design Quantification: Parameters Defining Exterior Proportions According to Car Segment”, in SAE 2014 World Congress \& Exhibition, Warrendale, United States. http://doi.org/10.4271/2014-01-0357

Luccarelli, M. and Matt, D., Russo Spena, P., Lienkamp, M. (2014b), "Purpose Design for Electric Cars: Parameters Defining Exterior Vehicle Proportions”, 3rd Conference on Future Automotive Technology Focus Electromobility, TU München, p.1-7. http://doi.org/10.13140/2.1.3077.4727

Macey, S. and Wardle, G. (2014), H-point: The fundamentals of car design \& packaging, Design Studio Press; Art Center College of Design, Culver City, California, Pasadena, California.

Mercedes-Benz (2021), The Mercedes-Benz F 015 Luxury in Motion. [online] Daimler AG. Available at: www.mercedes-benz.com (1th March 2021).

Morche, D.; Schmitt, F.; Genuit, K; Elsen, O.; Kampker, A.; Friedrich, B. (2013), “ Fahrzeugkonzeption für die Elektromobilität” in: Kampker, A., Vallée, D. and Schnettler, A. (Ed.), Elektromobilität: Grundlagen einer Zukunftstechnologie, Springer Vieweg, Berlin, pp. 149-234. https://doi.org/10.1007/978-3-642-31986-0

Oehme, A. (2011), Ästhetisches Verständnis und ästhetische Wertschätzung von Automobildesign. Eine Frage der Expertise, Potsdam Universität Potsdam.

SAE International (2009), Surface Vehicle Recommended Practice - Motor Vehicle Dimensions No. J1100 NOV2009.

Seeger, H. (2014), Basiswissen Transportation-Design: Anforderungen - Lösungen - Bewertungen, Springer Fachmedien, Wiesbaden. https://doi.org/10.1007/978-3-658-04449-7

Tzivanopoulos, T., Watschke, H., Krasteva, P. and Vietor, T. (2015), "Neue Denkansätze in der Fahrzeugkonzeption”, ATZ - Automobiltechnische Zeitschrift, Vol. 117, No. 9, pp. 16-21. http://doi.org/10.1007/s35148-015-0101-y

Van Hooydonk, A. (2012), In: Lenaerts, B.; Mol, L. D. (Eds.): Ever since I was a young boy I've been drawing cars, Delius Klasing, Bielefeld, pp. 216-239.

Volkswagen (2021), Der vollelektrische ID.4. [online] Volkswagen AG. Available at: www.volkswagen.de (1th March 2021).

Wallentowitz, H., Freialdenhoven, A. and Olschewski, I. (2010), Strategien zur Elektrifizierung des Antriebstranges: Technologien, Märkte und Implikationen, Vieweg+Teubner Verlag / GWV Fachverlage, Wiesbaden. http://doi.org/10.1007/978-3-8348-9910-1 